\title{
High Frequency Electronic Ballast Provides Line Frequency Lamp Current
}

\author{
Enrico Santi, Member, IEEE, Zhe Zhang, Member, IEEE, and Slobodan Ćuk, Fellow, IEEE
}

\begin{abstract}
Most electronic ballasts for fluorescent lamps provide a sinusoidal lamp current at the switching frequency. The high-frequency current flowing through the lamp can generate significant radiated noise, which is unacceptable in noise-sensitive applications, such as fluorescent lights in airplanes. Using shielded enclosures for the lamps may solve the problem, but it is expensive. A discontinuous conduction mode (DCM) electronic ballast topology is presented which drives the lamp with line frequency current, just like a magnetic ballast. However, compared to a magnetic ballast, its weight is substantially reduced due to operation at $40 \mathrm{kHz}$ switching frequency. The topology also ensures unity power factor at the input and stable lamp operation at the output.
\end{abstract}

Index Terms-Electromagnetic interference, electronic ballasts, power factor correction.

\section{INTRODUCTION}

I T IS well known [1], [2] that fluorescent lamps have a negative incremental impedance. Therefore, they cannot be connected directly to an ac voltage source: they require a ballast for stable operation. An additional requirement for fluorescent light ballasts, which has become common in recent years, is that of high input power factor. Fig. 1 shows different types of ballasts powered by a low frequency ac source.

Magnetic Ballast: In the past, so-called magnetic ballasts were used extensively. Basically, a magnetic ballast consists of a large inductor placed between the ac source and the lamp. The impedance of the inductor stabilizes the lamp. The lamp voltage and current are at the same frequency of the input ac source, as shown in Fig. 1(a). The input current is sinusoidal with little distortion and it has a lagging power factor due to the inductor. A capacitor at the input could be used to improve power factor. This is the ballast type commonly found on airplanes. A disadvantage of this solution is that the ballasting inductor must be sized for low-frequency operation, with associated penalty in terms of size and weight.

High-Frequency Electronic Ballast: In the recent technical literature, there are many examples of high-frequency electronic ballasts that use switching power converters [3], [4]. The high input power factor can be obtained either using a two-stage converter consisting of a unity-power-factor shaper followed by a high-frequency inverter or using a single stage, which usually operates in DCM at the input. As far as the output is concerned, the majority of these ballasts utilize a high-frequency resonant

Manuscript received December 20, 2000; revised June 1, 2001. Recommended by Associate Editor J. Qian.

E. Santi is with the Electrical Engineering Department, University of South Carolina, Columbia, SC 29208 USA (e-mail: esanti@engr.sc.edu).

Z. Zhang and S. Cuk are with TESLAco, Irvine, CA 92618 USA.

Publisher Item Identifier S 0885-8993(01)08056-5.

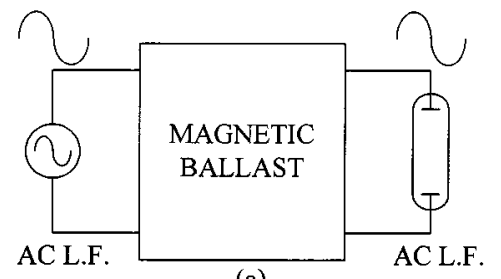

(a)

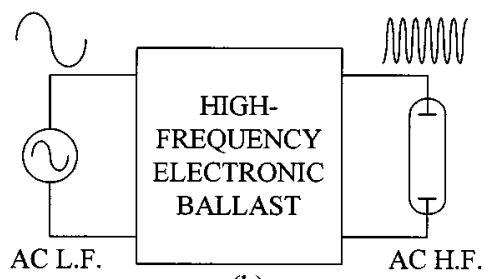

(b)

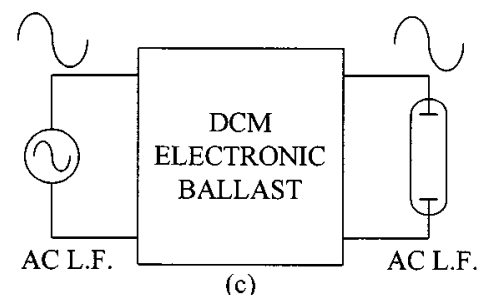

Fig. 1. (a) Low-frequency (L.F.) magnetic ballast, (b) high-frequency (H.F.) electronic ballast, and (c) proposed DCM electronic ballast with low-frequency (L.F.) lamp waveform.

filter in the output tuned to a frequency close to the switching frequency of the converter. Frequently, in order to achieve zero voltage switching operation, the switching frequency is chosen to be slightly higher than the resonant frequency of the output filter. See for example reference [3]. The effect of the resonant filter is to transform the switching converter output characteristic from a voltage source into a current source, thus ensuring stable lamp operation. In this approach the lamp current is a high frequency sinusoid at the switching frequency of the converter, as shown in Fig. 1(b).

Proposed DCM Electronic Ballast: A high-frequency lamp current, such as the one generated by the high-frequency electronic ballast described above, is desirable from the point of view of lamp efficacy, but it can generate significant radiated noise, since the entire lamp acts like an antenna. Problems connected with interference caused by electronic ballasts are reported in the literature [5]-[7]. High-frequency operation of the fluorescent lamp may produce electromagnetic interference (EMI), radio frequency interference (RFI), and infrared radiation (IR). A range of problems has been reported, in particular in connection with susceptibility of electronic communication and 
control equipment. For example, electronic lighting has caused malfunctions such as security systems becoming inoperative, hearing aids picking up and amplifying radiated emissions, TV, VCR, and CATV infrared controls misoperating, and so on [5]. This high-frequency noise is unacceptable in noise-sensitive applications, such as fluorescent lights in airplanes. The problem of EMI in airplanes has been studied in the literature [8], [9], and has caused concerns also to the general public. In recent times, the use of portable electronic equipment that generates electromagnetic interference has been restricted on commercial airplanes. Electromagnetic energy radiated from electrical and electronic equipment aboard aircrafts must comply with the Federal Communication Commission Rules and Regulations (CFR Title 47 Part 18). These problems were not present in old-fashioned magnetic ballasts operating from $400 \mathrm{~Hz}$ airplane power systems because the lamp voltage and current in these ballasts are at $400 \mathrm{~Hz}$, as shown in Fig. 1(a). Electric field emission measurements show that electronic ballasts exhibit significant emission levels at high frequencies (tens of $\mathrm{kHz}$ ) that are not present in magnetic ballasts. See [5, figures 7 and 8]. In avionic applications magnetic ballasts are still prevalent. Airplane manufacturers are reluctant to embrace electronic ballasts, and electromagnetic susceptibility problems are one of the main causes for concern. Another cause for concern in the use of high-frequency electronic ballasts is the potential for arcing at the fixture with associated fire and smoke hazard. This may happen, for example, if the lamp is improperly mounted or moves from the socket due to vibration. The problem of arcing is far less severe in line-frequency ballasts, because the arc is likely to extinguish at zero crossing due to the low frequency. With an high-frequency ballast the arc is far more likely to be sustained. It is desirable to combine the advantages of small size and weight of electronic ballasts with the advantages of low radiated noise and reduced arcing problem of magnetic ballasts. Conventional electronic ballasts could be designed to operate at a $400 \mathrm{~Hz}$ switching frequency to generate a $400 \mathrm{~Hz}$ sine wave current at the lamp, but the output resonant filter of the ballast would have to be designed for $400 \mathrm{~Hz}$ or lower frequency. At that point the size and weight would be comparable with magnetic ballasts and it may be difficult to justify the additional cost of an electronic ballast over a magnetic ballast. In this paper a discontinuous conduction mode (DCM) electronic ballast topology is presented that has a switching frequency of several $\mathrm{kHz}$, but gives a $400 \mathrm{~Hz}$ lamp current, just like a magnetic ballast. The high output impedance of the switching converter operating in DCM stabilizes the lamp. The topology also draws a sinusoidal current from the input ensuring high power factor. In the proposed topology all reactive elements are designed for high frequency (tens of $\mathrm{kHz}$ ) and therefore are small in size and weight. No component in the ballast has to provide line frequency energy storage.

In this paper the target application for the proposed ballast is avionics. The proposed ballast could be used also for conventional $60 \mathrm{~Hz}$ ballast applications. The gains in size and weight would be even more significant in that case. The proposed ballast is well-suited for applications where the radiated noise and the small size and weight are important.

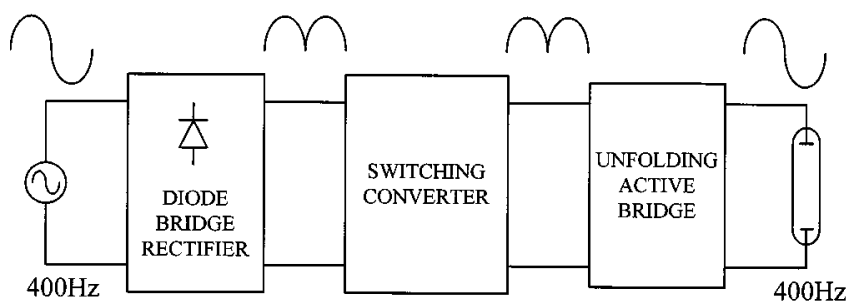

Fig. 2. Block diagram of proposed ballast.

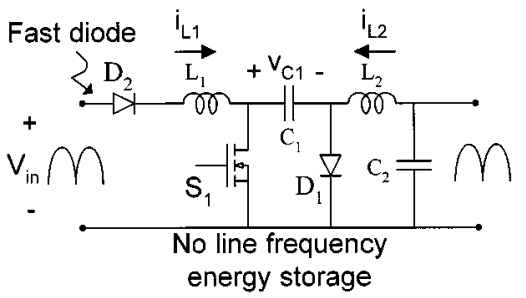

Fig. 3. Implementation of the "Switching Converter" block of Fig. 2 is a Ćuk converter operating in discontinuous conduction mode of diode $D_{2}$.

\section{PRoposed TOPOLOGY}

A block diagram of the proposed approach is shown in Fig. 2. The proposed topology consists of a diode bridge rectifier, a switching converter operating in discontinuous conduction mode and an unfolding active bridge, that takes the unidirectional output voltage of the converter and "unfolds" it, creating an ac output voltage, which is applied to the lamp. The unfolding active bridge operates at the frequency of the input ac voltage ( $400 \mathrm{~Hz}$ in the case of airplane applications) and the switching instants are synchronized to the input ac voltage. From the block diagram of Fig. 2 it is clear that the "SWITCHING CONVERTER" block must fulfill two distinct tasks.

- Draw a sinusoidal current from the input to satisfy input power factor requirements.

- Ensure stable lamp operation.

A switching converter that can accomplish these two tasks is the Cuk converter of Fig. 3 operated at constant duty cycle $D$. Notice that there is a fast diode $D_{2}$ in series with input inductor $L_{1}$ (a separate diode is not needed if the diode bridge rectifier of Fig. 2 has at least two fast diodes). This dc-dc converter topology has been used in [10] for an automatic current shaper. In that application, energy transferring capacitor $C_{1}$ was large because it was used for low-frequency energy storage. In other shaper applications capacitor $C_{2}$ is large. In our case all capacitors are small, so that the converter stores negligible energy at line frequency. As described in [10], the converter of Fig. 3 has various distinct discontinuous conduction modes, depending on which diode ceases conducting during the OFF interval. Since a continuous lamp current with small switching frequency ripple is desired, the discontinuous conduction mode due to input diode $D_{2}$ is used. Diode $D_{1}$ operates in continuous conduction mode, i.e., it conducts during the entire OFF interval. Under these conditions, this topology is equivalent to the cascade of a Boost converter operating in discontinuous conduction mode (DCM) and a Buck converter operating in continuous conduction mode (CCM). Analysis of this topology is 
given in [11], [14] and is briefly reviewed here. DCM coefficients $K_{1}$ and $K_{2}$ are defined as

$$
\begin{aligned}
K_{1} & =\frac{2 L_{1}}{R_{\text {load }}} f_{s} \\
K_{2} & =\frac{2 L_{2}}{R_{\text {load }}} f_{s}
\end{aligned}
$$

where $f_{s}$ is the switching frequency and $R_{\text {load }}$ is the equivalent load resistance. The condition for CCM operation of the Buck stage is

$$
K_{2}>K_{2 c r i t}=1-D
$$

and the condition for DCM operation of the Boost stage is

$$
K_{1}<K_{1 \text { crit }}=\frac{(1-D)^{2}}{D} .
$$

The dc gain of the Boost and the Buck stages are, respectively

$$
\begin{aligned}
& M_{1}=\frac{v_{C 1}}{v_{\text {in }}}=\frac{1+\sqrt{1+4 / K_{1}}}{2} \\
& M_{2}=D
\end{aligned}
$$

and the overall gain is

$$
M=M_{1} M_{2}=\frac{1+\sqrt{1+4 / K_{1}}}{2} D .
$$

\section{Proposed Converter as an Ideal Automatic CURRENT SHAPER}

We can make the following general statement.

Take any switching converter with no line frequency energy storage operated at constant duty cycle D, constant switching frequency $f_{s}$ and with a constant resistive load $R$. Assume also that the converter operates either in continuous conduction mode or in discontinuous conduction mode throughout the entire line period, i.e., it does not change mode of operation. Such a converter is an ideal current shaper.

Proof: The key assumption is that the converter has no line frequency energy storage. Discontinuous conduction mode factor $K$ and voltage gain $M$ are given by

$$
K=f_{1}\left(R, f_{s}, L\right) \quad M=v_{0} / v_{\text {in }}=f_{2}(D, K)
$$

where $L$ is some inductor or combination of inductors in the switching converter. According to our assumptions $K$ is a constant and so is $M$. Since the converter has no energy storage and the load is purely resistive, the dc voltage gain $M$ represents also the instantaneous voltage gain of the converter. The input impedance of the converter is

$$
R_{\text {in }}=\frac{R}{M^{2}}
$$

and it is a constant. Therefore, the converter acts like a constant resistor and it is an ideal current shaper.

QED

The general statement given above proves that the converter of Fig. 3 is indeed an ideal current shaper. It is instructive to compare this circuit, which has no line frequency energy

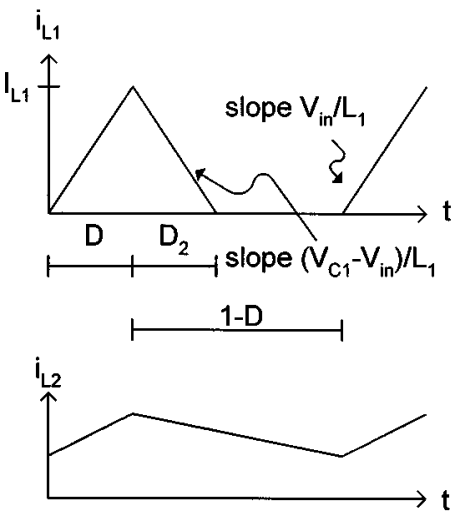

Fig. 4. Input and output inductor current waveforms of the Ćuk converter of Fig. 2 operating in discontinuous conduction mode of diode $D_{2}$.

storage, with a very similar topology with internal energy storage. Let us consider the automatic current shaper described in [10], which is identical to the converter of Fig. 3, except that energy transferring capacitor $C_{1}$ is large and stores energy at line frequency. That converter can also be analyzed as a DCM Boost followed by a CCM Buck. Line energy is stored in capacitor $C_{1}$, the output of the DCM Boost. However, the converter with internal energy storage is not an ideal shaper, whereas the converter without energy storage is. We can prove this by studying the input current waveform shown in Fig. 4, which applies to both converters. The peak input current $I_{L 1}$ is

$$
I_{L 1}=\frac{v_{\text {in }} D}{L_{1} f_{s}} .
$$

The interval $D_{2}$ during which current $i_{L 1}$ decays to zero can be calculated by applying the volt-second balance equation to inductor $L_{1}$

$$
D_{2}=\frac{v_{\text {in }} D}{v_{C 1}-v_{\text {in }}}
$$

The input current averaged during a switching period is

$$
\bar{\imath}_{L 1}=\frac{I_{L 1}\left(D+D_{2}\right)}{2} .
$$

Substituting (10) into (12) we finally obtain

$$
\bar{\imath}_{L 1}=v_{\text {in }} \frac{D}{2 L_{1} f_{s}}\left(D+D_{2}\right) .
$$

In an ideal shaper current $\bar{\imath}_{L 1}$ must be proportional to input voltage $v_{\text {in }}$. Let us examine the right hand side of (13): the first term is proportional to input voltage $v_{\text {in }}$, the second term is constant, the third term is constant if $D_{2}$ is constant. Therefore the condition is satisfied if $D_{2}$ is a constant. From (11), $D_{2}$ is constant if $v_{C 1}$ is proportional to input voltage $v_{\text {in }}$, which is true for the converter with no line energy storage, as can be seen from (5), but it is not true in the case of the converter with internal energy storage, because voltage $v_{C 1}$ is constant throughout the line period while $v_{\text {in }}$ is a rectified sine wave.

The automatic current shaper performance was verified experimentally on the prototype. With a resistive load the input current THD measured on the prototype was $3.2 \%$. The measured input current is shown in Fig. 5. With a lamp load the 


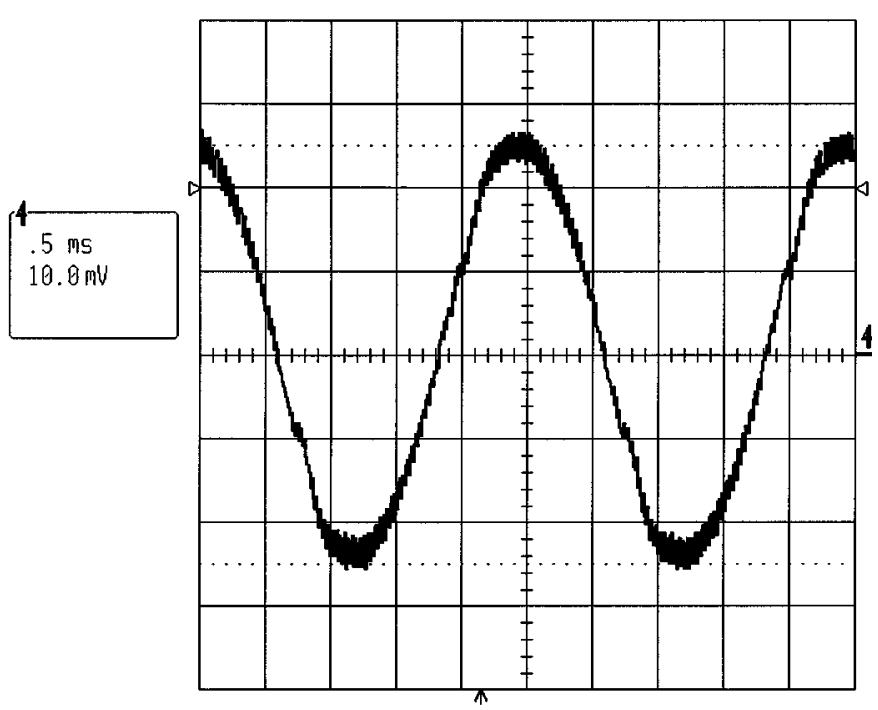

Fig. 5. Input current waveform measured on the prototype with a resistive load $(0.2 \mathrm{~A} / \mathrm{div})$. Measured THD is $3.2 \%$.

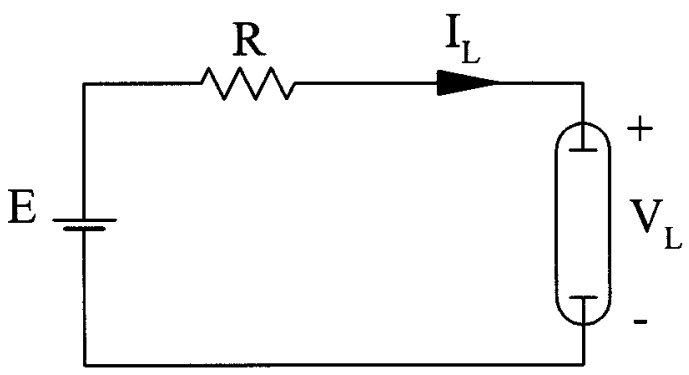

Fig. 6. DC resistive ballast.

nonlinear load resistance introduces some more distortion. The measured THD with lamp load was $8.8 \%$.

\section{Proposed Converter Stabilizes Lamp CuRREnT}

The proposed converter stabilizes the lamp current because the converter operating in DCM has a positive output impedance that compensates the negative incremental impedance of the lamp. In order to study the stability of the DCM ballast, a simpler case is examined first: a resistive ballast operating from a dc input source. See also [1, pp. 11-16].

\section{A. Stability of DC Resistive Ballast}

A dc resistive ballast is shown in Fig. 6. It consists of a ballast resistor $R$ connected between the input dc voltage $E$ and the lamp. In a real implementation, additional circuitry may be needed to strike the lamp. The loop equation of this circuit is

$$
E=R I_{L}+V_{L}
$$

The lamp characteristic is nonlinear

$$
V_{L}=f\left(I_{L}\right) .
$$

The dc lamp characteristic and the characteristic of the rest of the circuit are shown in Fig. 7(a) and (b) for different values

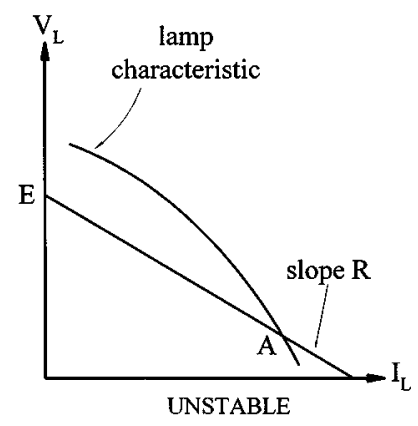

(a)

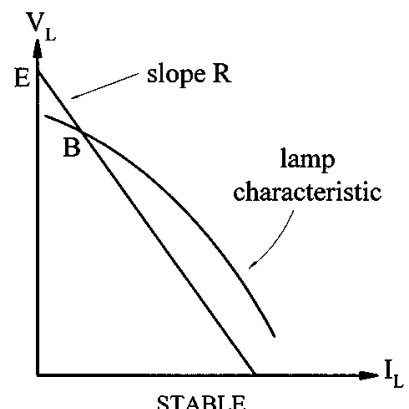

(b)
Fig. 7. DC lamp characteristic and the characteristic of the remaining circuit of the dc ballast of Fig. 6 for two different values of ballast resistor $R$. The first value gives unstable operation, while the second one gives stable operation.

of $R$. The intersections of the two curves represent possible operating points. It can be easily seen that point $A$ of Fig. 7(a) is an unstable operating point, whereas point $B$ of Fig. 7(b) is a stable operating point.

In general, the equilibrium point is stable if the slope of the lamp characteristic is less than the slope of the characteristic of the rest of the circuit. That means that the stability condition is that the lamp incremental impedance (which is the slope of the lamp characteristic and it is negative) must be smaller in magnitude than the ballast resistance $R$.

Let us perform a small signal analysis, which will give the same results. Perturbation of (14) and (15) gives

$$
\begin{aligned}
\hat{v}_{L} & =\frac{\partial f}{\partial I_{L}} \hat{\imath}_{L}=\tilde{R}_{L} \hat{\imath}_{L} \\
\hat{E} & =R \hat{\imath}_{L}+\hat{v}_{L} .
\end{aligned}
$$

$\tilde{R}_{L}$ is the lamp incremental impedance and it is negative. Combining (16) and (17) we obtain

$$
\hat{E}=\left(R+\tilde{R}_{L}\right) \hat{\imath}_{L} .
$$

The stability condition is

$$
R>\left|\tilde{R}_{L}\right|
$$

and it says that the lamp incremental impedance $\tilde{R}_{L}$ must be smaller in magnitude than the ballast resistor $R$.

\section{B. Stability of Proposed Ballast}

Let us now consider the stability of the proposed DCM ballast of Figs. 2 and 3. The situation is more complicated than in the dc case: the ballast operates at $400 \mathrm{~Hz}$, there is a rectifying stage in front of the DCM converter and an active unfolding stage after it. We can make the following observations:

The Rectifying and Unfolding Stages are Irrelevant for the Stability Analysis: We can consider just the DCM converter of Fig. 3 and the lamp.

We are Interested Only in the Low-Frequency Behavior of the Ballast: As explained in [2], the negative incremental impedance of the lamp is a low-frequency phenomenon. As a matter of fact, the $400 \mathrm{~Hz}$ steady-state characteristic of the lamp is a somewhat nonlinear positive resistance as shown in 


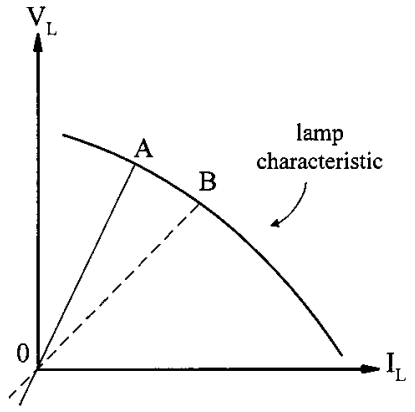

Fig. 8. Plot of the lamp steady state operating point under $400 \mathrm{~Hz}$ operation.

Fig. 16. The situation is shown in Fig. 8. Line A-0 represents the steady-state operation of the lamp under sinusoidal excitation. Its slope is the steady-state lamp resistance $R_{L}$ and it is positive. Curve A-B represents the low-frequency characteristic of the lamp and its slope is the negative incremental impedance of the lamp $\tilde{R}_{L}$.

The DCM Converter Has No Dynamics at Low Frequency: Since after a $400 \mathrm{~Hz}$ cycle the converter ends in the same condition as it started with no energy storage, there is no reactive element in the low frequency model of the DCM converter. The dc characteristics completely characterize the behavior of interest.

The Low-Frequency Small-Signal Behavior of the Lamp is Modeled as a Negative Constant Resistance: A very simple model for the lamp is chosen. In the literature, some more sophisticated models are proposed [12], [13]. However, these models are derived for high-frequency electronic ballast operation (tens of $\mathrm{kHz}$ ) and not for the $400 \mathrm{~Hz}$ operation considered here. In order to justify this choice the low-frequency small-signal lamp characteristic was measured with a network analyzer in the case of a dc ballast. The lamp used was a Sylvania T-8 $32 \mathrm{~W}$ lamp operated at a dc current of $0.24 \mathrm{~A}$. The lamp voltage was $150 \mathrm{~V}$. The result is shown in Fig. 9 for a frequency range $10-100 \mathrm{~Hz}$. It can be seen that the lamp is approximately a constant negative resistance around $-80 \Omega$. At the highest measured frequency the phase shift is only $30^{\circ}$, so the approximation of modeling the lamp as a resistance appears justified.

In order to proceed with the stability analysis in a way analogous to the dc ballast, we need to describe the converter output characteristic and the lamp characteristic, i.e., we need to find expressions analogous to (14) and (15) used for the dc ballast.

Defining the quantity

$$
A=\frac{2}{L_{1} f_{s}}
$$

we obtain from the dc gain equation (7)

$$
V_{L}=V_{\mathrm{in}} \frac{1+\sqrt{1+A R_{\text {load }}}}{2} D
$$

where $V_{\text {in }}$ and $V_{L}$ are the rms input and output voltage of the converter respectively, and $R_{\text {load }}$ is the equivalent load resistance.
The converter rms output current is given by

$$
I_{L}=\frac{V_{L}}{R_{\text {load }}} .
$$

Since we operate at constant duty cycle $D,(21)$ and (22) give the converter output characteristic in parametric form with converter load resistance $R_{\text {load }}$ as a parameter. These two equations together are analogous to the load line equation (14) in the dc ballast case.

The low-frequency lamp characteristic for $400 \mathrm{~Hz}$ lamp operation is obtained experimentally measuring rms lamp voltage and current while operating the lamp with a magnetic ballast. The measured operating points are shown in Table I. The DCM converter output characteristic given by (21) and (22) is plotted together with the lamp characteristic in Fig. 10 for the design described in the experimental verification in the following section. It can be clearly seen that the slope of the converter characteristic is steeper than the lamp characteristic, denoting stable operation. Notice how the stability analysis follows the same lines of the dc ballast. As in the dc ballast case a small-signal analysis will lead to the same conclusions. The converter small-signal output characteristic can be obtained as follows. Equations (21) and (22) are perturbed

$$
\begin{gathered}
\hat{v}_{L}=\left.\frac{\partial V_{L}}{\partial D}\right|_{\hat{R}_{L}=0} \hat{D}+\left.\frac{\partial V_{L}}{\partial R_{\text {load }}}\right|_{\hat{D}=0} \hat{R}_{\text {load }} \\
\hat{\imath}_{L}=\left.\frac{\partial I_{L}}{\partial D}\right|_{\hat{R}_{L}=0} \hat{D}+\left.\frac{\partial I_{L}}{\partial R_{\text {load }}}\right|_{\hat{D}=0} \hat{R}_{\text {load }} \cdot
\end{gathered}
$$

If we solve (24) for $\hat{R}_{\text {load }}$ and we substitute in (23), we obtain

$$
\hat{v}_{L}=E_{0} \hat{D}-R_{0} \hat{\imath}_{L}
$$

where

$$
\begin{aligned}
& R_{0}=\frac{A R_{L}^{2}}{2+2 \sqrt{1+A R_{L}}+A R_{L}} \\
& E_{0}=V_{\text {in }} \frac{1+\sqrt{1+A R_{L}}}{2}\left(1+\frac{R_{0}}{R_{L}}\right) .
\end{aligned}
$$

In these equations, we have made the substitution $R_{L} \rightarrow R_{\text {load }}$ since the equivalent steady state load resistance of the converter is the steady-state lamp resistance. Equation (25) shows that the small signal model of the DCM converter is given by a voltage source $E_{0} \hat{D}$ followed by the converter output resistance $R_{0}$. This resistance performs the ballasting function and stabilizes lamp operation. The small-signal equivalent circuit is shown in Fig. 11. The lamp is represented by its incremental resistance $\tilde{R}_{L}$, which is negative. The stability condition is analogous to (19) and it is

$$
R_{0}>\left|\tilde{R}_{L}\right|
$$

Notice the difference between $\hat{R}_{\text {load }}$ and $\tilde{R}_{L}$. The first quantity $\hat{R}_{\text {load }}$ represents a small perturbation of the converter load resistance around its operating point, while the second quantity $\tilde{R}_{L}$ is the incremental impedance of the lamp, which is a negative finite quantity. 


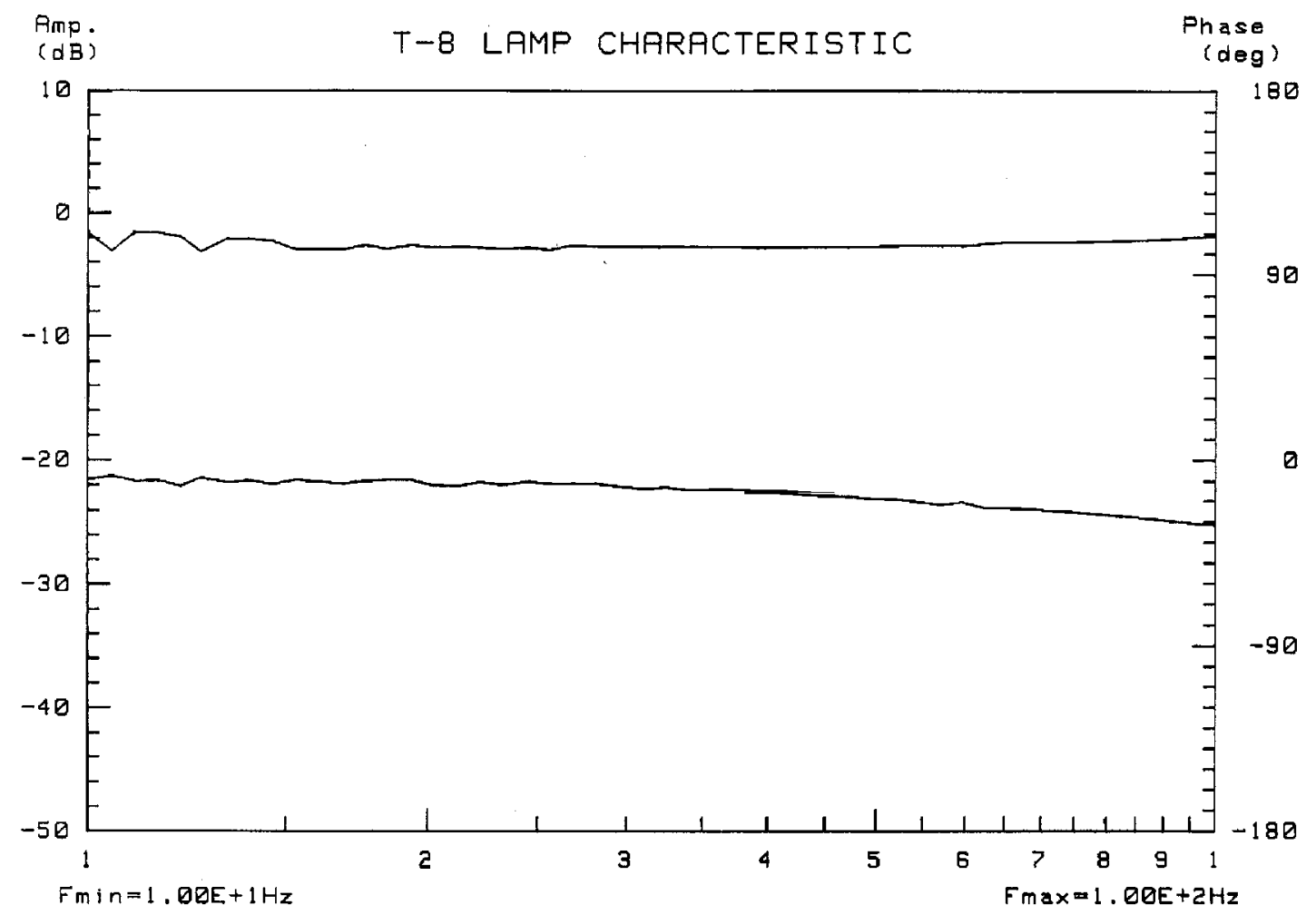

Fig. 9. Small-signal $v / i$ characteristic of a Sylvania T-8 $32 \mathrm{~W}$ lamp powered by a dc resistive ballast measured with a network analyzer. No separate filament heating is used. Voltage was measured with a 100:1 probe and current with a 1:1 probe. Top trace is magnitude; bottom trace is phase.

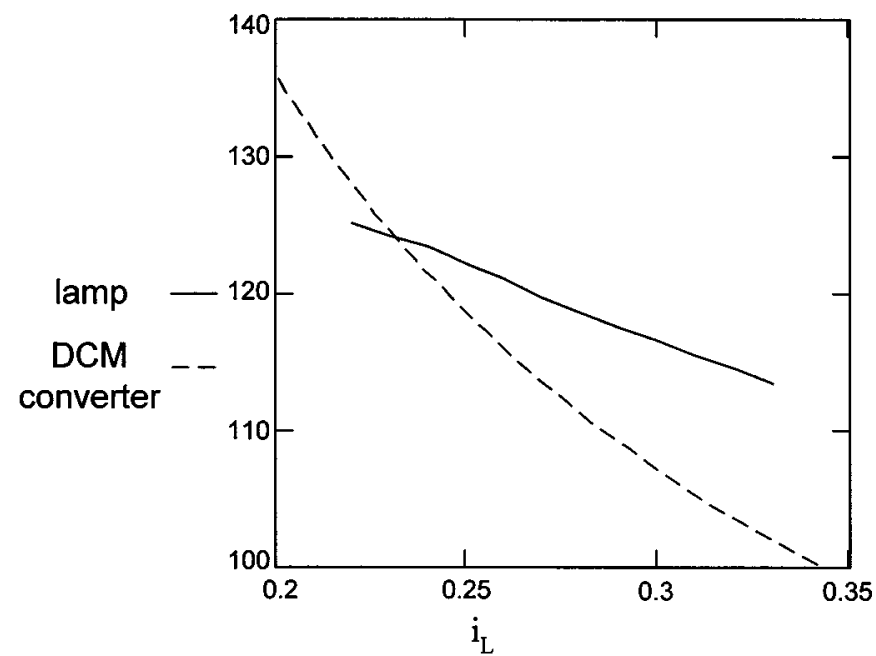

Fig. 10. The $400 \mathrm{~Hz}$ ac lamp characteristic and the output characteristic of the converter. $X$-axis represents lamp current in Amperes and $Y$-axis represents lamp voltage in volts.

\section{Design and PRACTiCAl IMPLEMENTATion}

A prototype was built and tested. The lamp used is a Sylvania $\mathrm{T}-832 \mathrm{~W}$ rapid start lamp. The nominal voltage and current are $125 \mathrm{Vrms}$ and 0.24 Arms, which gives a nominal steady-state lamp resistance $R_{L}=125 / 0.24=520 \Omega$. Input voltage is 115 Vrms, $400 \mathrm{~Hz}$. Nominal frequency is $f_{s}=40 \mathrm{kHz}$ and nominal duty cycle is $D=0.45$. From (21) we have

$$
A=\frac{1}{R_{L}}\left[\left(\frac{2 V_{L}}{V_{\mathrm{in}} D}-1\right)^{2}-1\right]
$$

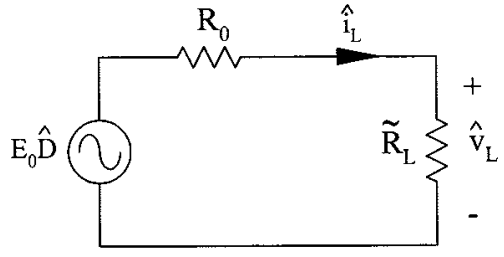

Fig. 11. Small-signal model of the DCM ballast.

TABLE I

MEASURED LAMP ChaRACTERISTIC USING MAGNETIC BALLAST OPERATING AT $400 \mathrm{~Hz}$

\begin{tabular}{c|c|c|c|c|c|c}
\hline$V_{L}[V]$ & 125.1 & 124.3 & 123.5 & 122.2 & 121.1 & 119.6 \\
\hline$I_{L}[A]$ & 0.22 & 0.23 & 0.24 & 0.25 & 0.26 & 0.27 \\
\hline \hline$V_{L}[V]$ & 118.6 & 117.6 & 116.6 & 115.5 & 114.6 & 113.4 \\
\hline$I_{L}[A]$ & 0.28 & 0.29 & 0.30 & 0.31 & 0.32 & 0.33 \\
\hline
\end{tabular}

which gives $A=0.026 \Omega^{-1}$. From (20) we get

$$
L_{1}=\frac{2}{A f_{s}}
$$

which gives $L_{1}=1.9 \mathrm{mH}$. Condition (4) for DCM operation of the Boost stage is met for this value of $L_{1}$. Stability condition (28) is satisfied: the output impedance of the DCM converter at the operating point is calculated using (26) and it is $304 \Omega$; the lamp incremental impedance calculated from the measured lamp characteristic of Table I is $-80 \Omega$. 


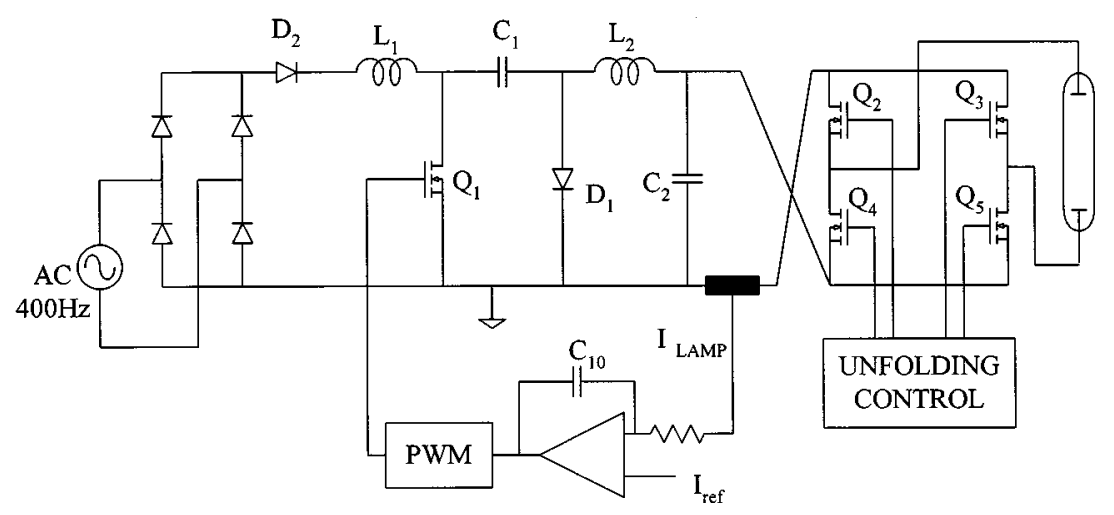

Fig. 12. Simplified schematic of the ballast.

A simplified schematic of the ballast implementation is shown in Fig. 12. Diode $D_{2}$ is the fast diode that forces DCM operation. Capacitors $C_{1}, C_{2}$ are sized to have a relatively small voltage ripple at the switching frequency. Inductor $L_{2}$ must ensure continuous conduction mode operation of the Buck stage. From condition (3) the minimum value of $L_{2}$ is $3.9 \mathrm{mH}$. The value of inductor $L_{2}$ also determines the lamp current ripple at the switching frequency. Since the purpose of this design was to obtain a ballast with line frequency lamp current, a rather large value of $L_{2}$ is desirable. A value of $L_{2}$ of $30 \mathrm{mH}$ was selected. The unfolding control turns on switches $Q_{2}-Q_{5}$ and $Q_{3}-Q_{4}$ alternatively every time the AC input voltage crosses zero. Since these switches operate at twice the line frequency, they do not need to be fast. A dead time is introduced to avoid cross-conduction.

The PWM control may be operated either open-loop at constant duty cycle or closed-loop. In both cases a voltage-limiting loop (not shown in the simplified schematic) should be implemented to limit the output voltage and protect switch $Q_{1}$ in case the lamp is removed. A possible implementation of a closed-loop lamp current control is shown in Fig. 12. The control keeps the average (rectified) lamp current at a desired value $I_{\text {ref. }}$.

The small-signal model of Fig. 11 can be used to analyze the system. The only difference is that now we are considering averaged quantities and therefore $V_{\text {in }}$ in (27) should represent the average input voltage. The block diagram of Fig. 13 represents the small-signal closed-loop behavior of the lamp. Block $G(s)$ is the compensation, that in our implementation is a pure integrator. The input to this block is the lamp current error and the output is the duty cycle $\hat{D}$. The remaining two blocks represent the small signal ballast model of Fig. 11. It is clear from this model that, as long as condition (28) is satisfied, it is a simple task to close the feedback loop. The control has a bandwidth of $10-30 \mathrm{~Hz}$, since it must be much smaller than $400 \mathrm{~Hz}$ to avoid distortion. In closed-loop operation, dimming of the lamp is possible.

Components used in the prototype are $D_{2}=\mathrm{BYV} 26 \mathrm{D}, Q_{1}=$ BUZ80, $Q_{2}, Q_{3}, Q_{4}, Q_{5}=\mathrm{IRF} 840, C_{1}=47 \mathrm{nF}, C_{2}=22 \mathrm{nF}$, $L_{1}=1.8 \mathrm{mH}, L_{2}=30 \mathrm{mH}$. Notice that the value of inductor $L_{1}$ turned out to be slightly smaller than the one calculated above. The only effect of this is that the nominal duty cycle will

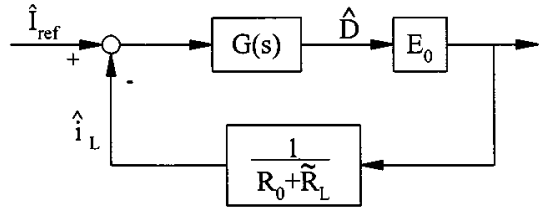

Fig. 13. Block diagram of the closed-loop DCM ballast.

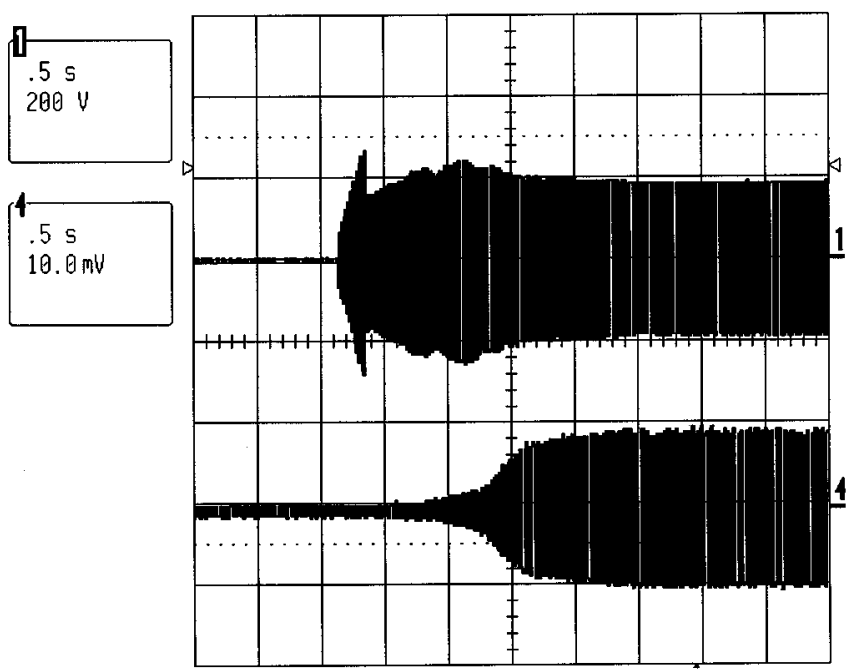

Fig. 14. Lamp turn-on transient. Upper trace: lamp voltage $200 \mathrm{~V} /$ div; lower trace: lamp current $0.5 \mathrm{~A} / \mathrm{div}$.

be slightly different. A $400 \mathrm{~Hz}$ transformer is used to provide heating for the lamp filaments.

The efficiency of the proposed ballast is not very high. A first reason is that the topology has two stages, the Cuk converter and the unfolding stage at the output. A second reason is that all switches have high voltage ratings. The unfolding stage switches have a voltage stress equal to the peak lamp voltage. The peak stress on these switches happens during startup, before the lamp strikes, as shown in Fig. 14. The stress on the Ćuk converter switches is equal to the sum of peak input and lamp voltage. Once again, the highest stress will be at startup. In the design the unfolding switches were $500 \mathrm{~V}$ MOSFET's, and the Ćuk converter switches were rated at $800 \mathrm{~V}$.

The cost of this solution is not low because of the two stages and the number of components. However, the intended applica- 


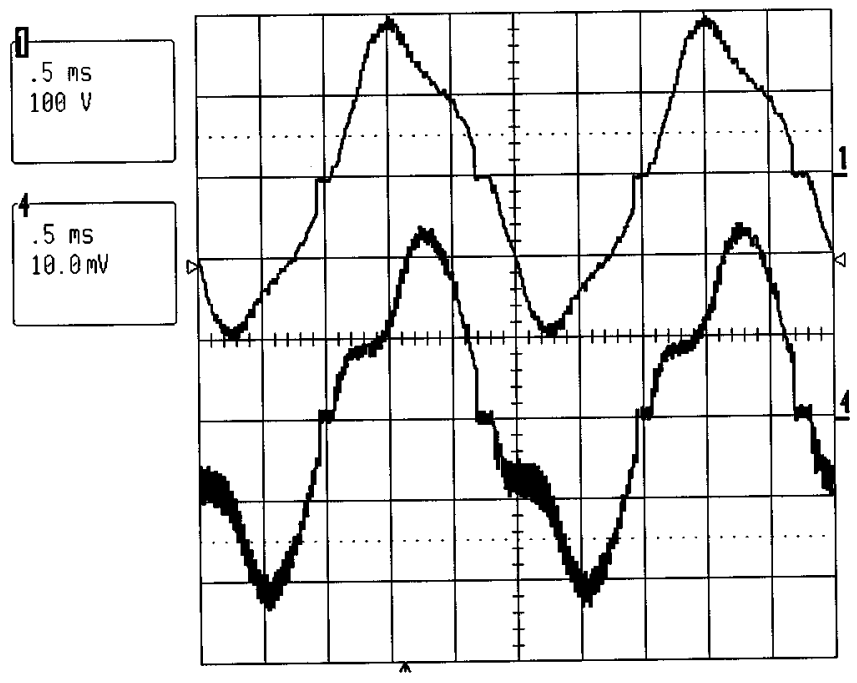

Fig. 15. Steady-state operation. Upper trace: lamp voltage $100 \mathrm{~V} /$ div; lower trace: lamp current $0.2 \mathrm{~A} / \mathrm{div}$.

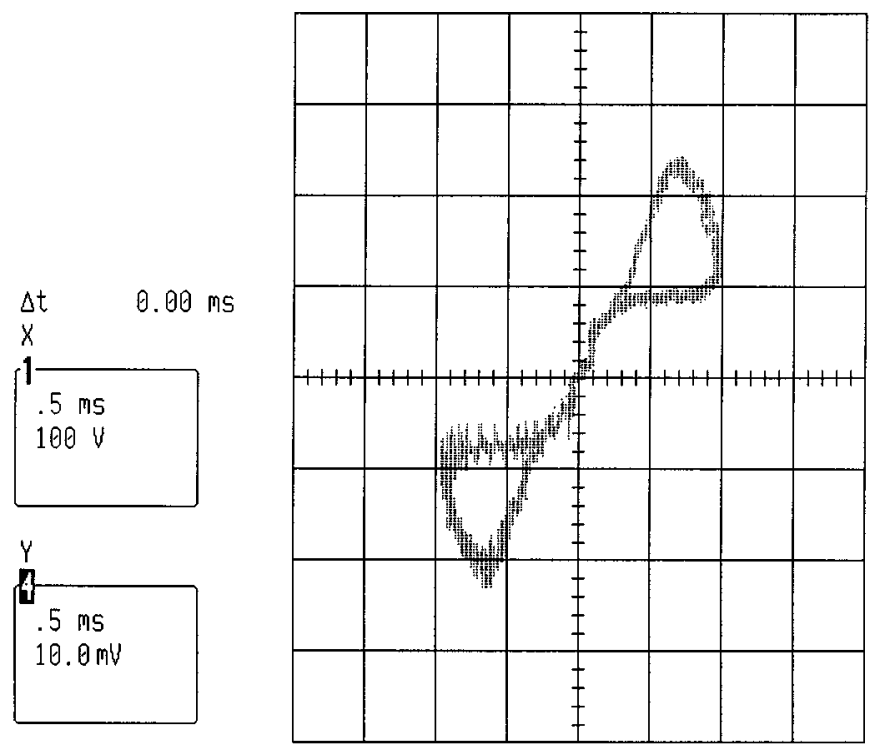

Fig. 16. Steady-state operation. $X-Y$ plot. $X$-axis: lamp voltage $100 \mathrm{~V} /$ div; $Y$-axis: lamp current $0.2 \mathrm{~A} /$ div.

tion is not very price sensitive. A ballast for avionic use can cost twenty times as much as a comparable consumer market ballast.

\section{EXPERIMENTAL RESULTS}

Lamp turn-on is shown in Fig. 14. No special provision is needed to provide the high voltage needed to strike the lamp. The DCM operation provides this high voltage naturally: before the lamp strikes, the DCM converter sees a very high load resistance and the converter output voltage in that condition is very high, as can be seen from (21).

Lamp voltage and lamp current in nominal operation are shown in Fig. 15. The distortion in the voltage and current waveforms are typical of low-frequency ballasts, as can be seen in the figure in [1, page 104]. The cross-over distortion is due to the dead time in the unfolding stage. Fig. 16 shows

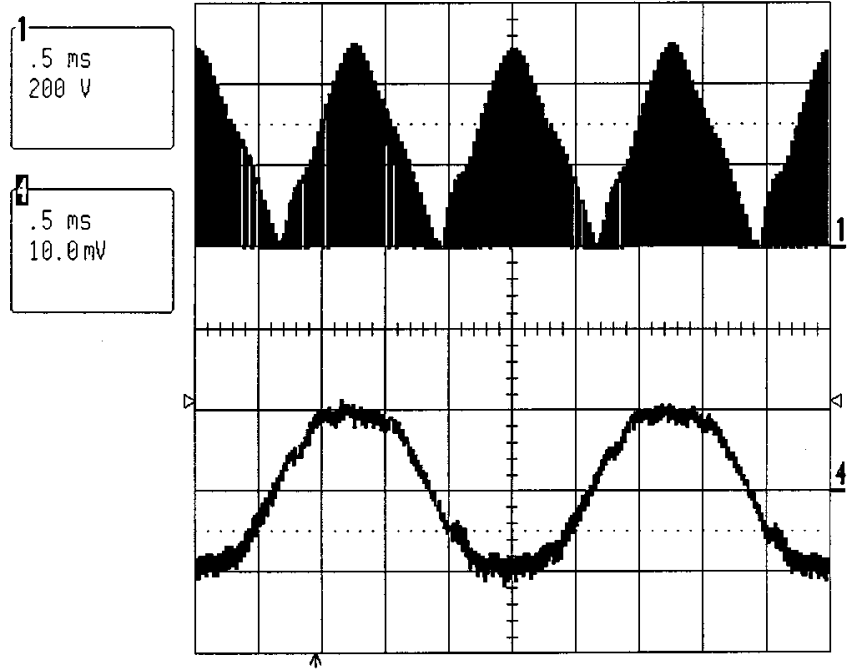

Fig. 17. Steady state operation. Upper trace: main switch voltage $200 \mathrm{~V} / \mathrm{div}$; lower trace: input current $0.5 \mathrm{~A} / \mathrm{div}$. Measured input current THD is $8.8 \%$.

lamp voltage and lamp current in $X-Y$ coordinates. Notice the nonlinear lamp characteristic. Switch voltage and input current are shown in Fig. 17. The input current THD is 8.8\%.

\section{CONCLUSION}

An electronic ballast topology for fluorescent lamps has been proposed that provides input unity power factor and stable lamp operation. An advantage of the proposed topology is that the lamp voltage and current are at the line frequency, eliminating the radiated noise problem of electronic ballasts with high-frequency lamp current. In addition, the high switching frequency of operation of $40 \mathrm{kHz}$ reduces the weight of the ballast. Both of these performance features are critical for some special applications, such as fluorescent lamp ballast for airplanes.

\section{REFERENCES}

[1] W. Elenbaas, Fluorescent Lamps and Lighting. London, U.K.: Macmillan, 1959

[2] E. Deng and S. Ćuk, "Negative incremental impedance and stability of fluorescent lamps," in Proc. IEEE Appl. Power Electron. Conf. (APEC), 1997.

[3] _ "Single stage, high power factor, lamp ballast," in Proc. APEC'94, 1994.

[4] J. M. Alonso et al., "Analysis and experimental results of a single-stage high-power-factor electronic ballast based on flyback converter," in Proc. APEC'98, 1998.

[5] R. J. Schwabe et al., "Electronic lighting interference," IEEE Ind. Applicat. Mag., pp. 43-48, July/Aug. 1998.

[6] E. Hammer and W. Anderson, "Interaction of infrared controls and electronic compact fluorescent lamps," in Proc. IEEE Ind. Applicat. Soci. Conf. (IAS), Orlando, FL, 1995.

[7] S. Kataoka and H. Atagi, "Prevention of IR interference from high frequency fluorescent lighting to IR remote-control systems," in Proc. APEC'95, 1995, pp. 677-683.

[8] R. W. Devereux, B. Archambeault, and G. L. Fuller, "Assessment of analytical codes for use in modeling aircraft onboard EMI threats," in Proc. Dig. Avion. Syst. Conf., 16th DASC., AIAA/IEEE, vol. 1, 1997, pp. $4.317-24$.

[9] R. W. Devereux, G. L. Fuller, and R. Schillinger, "Electromagnetic susceptibility of installed avionics," in Proc. Dig. Avion. Syst. Conf., 16th DASC., AIAA/IEEE, vol. 1, 1997, pp. 4.1 17-24.

[10] M. Brkovic and S. Ćuk, "Automatic current shaper with fast output regulation and soft switching," in Proc. INTELEC'93, 1993, pp. 379-386. 
[11] S. Ćuk, "Discontinuous inductor current mode in the optimum topology switching converter," in Proc. IEEE Power Electron. Spec. Conf., 1978, pp. $160-179$.

[12] C. S. Moo et al., "A fluorescent lamp model for high-frequency electronic ballasts," in Proc. IAS'00, vol. 5, Oct. 8-12, 2000, pp. 3361-3366.

[13] H. J. Lee et al., "A coupled radiation transport particle-in-cell model for fluorescent lamp discharges," in Proc. ICOPS'00, June 4-7, 2000, p. 246.

[14] R. D. Middlebrook and S. Cuk, "Advances in Switched-mode power conversion," in Proc. TESLAco, 1983, pp. 365-384.

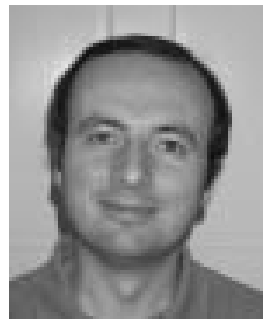

Enrico Santi (M'88) received the Dr.Ing. degree in electrical engineering from the University of Padua, Italy, in 1988 and the M.S. and Ph.D. degrees from the California Institute of Technology (Caltech), Pasadena, in 1989 and 1994, respectively.

He worked as a Senior Design Engineer at TESLAco, Irvine, CA, from 1993 to 1998, where he was responsible for the development of various switching power supplies for commercial applications. Since 1998, he has been an Assistant Professor in the Electrical Engineering Eepartment, University of South Carolina, Columbia. He has published several papers in power electronics and holds two patents. His research interests include switching-mode power converters, simulation of advanced power systems, and modeling of power semiconductor devices.

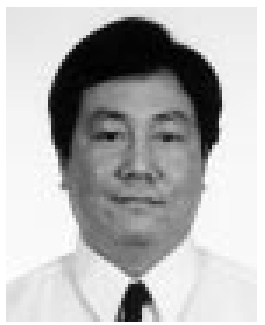

Zhe Zhang (M'99) received the Ph.D. degree from the California Institute of Technology (Caltech), Pasadena.

He then joined TESLAco, Irvine, CA, as Chief Engineer, where he is now Director of Engineering. He is a world expert and authority on the magnetic circuit design in general and integrated magnetics in particular, in which he has made many original contributions. He has also mastered all other aspects of the state-of-the-art switching power supply design, such as a sophisticated two-loop feedback control design, design of efficient EMI filters, and has practical knowledge of the layout design for high-frequency applications. He has made many practical designs based on the coupled-inductors and soft switching $\boldsymbol{C} \boldsymbol{U}$ Konverter ${ }^{\circledR}$ ranging from high performance mil-spec designs through high reliability converter power modules for telecommunications application to low cost personal computer power supplies. His designs are now manufactured, on a License from TESLAco, by a number of companies in Europe, Japan, and the United States. He has several patents pending and has published over 20 technical papers.

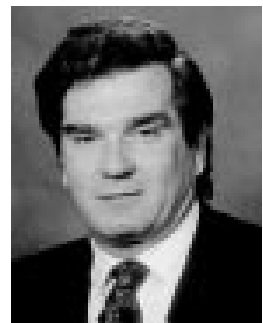

Slobodan Ćuk (F'96) was Professor of electrical engineering at the California Institute of Technology (Caltech), Pasadena, for 23 years. In 1980, he founded TESLAco with the charter to apply the basic research results developed at Caltech to practical commercial and military designs. He conducts research in electronic energy processing systems, and teaches courses in power electronics, electrical machines, and motor drives. His publications include over 100 scientific papers in the Power Electronics field and a three volume book on switched-mode power conversion. He holds six patents related to the new switching power conversion concept. A dozen new patents are also pending.

Dr. Cuk received the coveted $\mathrm{IR}^{*} 100$ Award from Industrial Research Magazine, in 1980, for the invention of a new switching converter topology, known as the $\boldsymbol{C} \boldsymbol{U}$ Konverter ${ }^{\circledR}$, and several of its extensions, and the prestigious 1991 Edward Longstreth Medal from the Franklin Institute (which was for the first time in its 100 years history awarded to researcher in Power Electronics) for "pioneering and expediting the development of Integrated magnetics and switched-mode power supplies compatible with the small size of the rapidly advancing signal processing technology." 